\title{
Proteção previdenciária, gênero e renda na idade avançada
}

\author{
Eliane Romeiro Costa \\ Doutora em Direito \\ Professora da UCG. \\ amarili@yahoo.com \\ Giovana Guimarães de Miranda \\ Bolsista PIBIC/CNPq/UCG \\ Graduanda em Direito da UCG \\ gioguio6@hotmail.com
}

\begin{abstract}
Resumo A insuficiência de renda e a falta de autonomia para lidar com as atividades do cotidiano, fazem com que os idosos necessitem de algum tipo de proteção social. Há entretanto, diferenças conceituais entre os gêneros para a previdência social, refletindo em desigualdades no acesso aos benefícios previdenciários. Dessa forma, as políticas públicas previdenciárias assumem especial relevância com o intuito de reverter esse quadro de desigualdade.
\end{abstract}

Palavras-chave: previdência social; desigualdades por gênero e benefícios; idosos; políticas públicas; proteção social.

$\mathrm{O}$ DeSAFIOS TRAZIDOS PELO ENVELheCimento da população têm diversas dimensões e dificuldades. O envelhecimento da população como fenômeno sociológico provoca o mercado, o consumo, reflete nas aposentadorias, nas pensões, bem como no conjunto de direitos sociais.

A política pública de atendimento ao idoso influencia o desenvolvimento socioeconômico e cultural. Marco significativo nesta trajetória é a Constituição Federal de 1988, que introduziu em suas disposições o conceito de Seguridade Social, fazendo com que a rede de proteção social alterasse o seu enfoque estritamente assistencialista, passando a ter uma conotação ampliada de cidadania.

Segundo a análise de doutrinadores, Seguridade Social é um sistema em que o Estado garante a 'libertação da necessidade'. O Estado é obrigado a garantir que seus cidadãos tenham suas necessidades mínimas satisfeitas, independentemente da contribuição do beneficiário. Todas as receitas do sistema sairão do orçamento geral do Estado, ou seja, são direitos garantidos pelo simples exercício da cidadania.

Contudo, tem-se que o direito à Seguridade Social é público, subjetivo, irrenunciável, inalienável e intransmissível de tal modo que assegurando a satisfação das necessidades essenciais do indivíduo seja capaz de conduzi-lo à concretização do princípio da dignidade da pessoa humana.

Consoante artigo 194 da Constituição Federal, a Previdência integra o Sistema de Seguridade Social, em conjunto com as ações promotoras de saúde e de assistência social. De acordo com o artigo 201, o Sistema Previdenciário visa cobrir o risco social 'idade avançada', garantindo a renda daqueles que contribuíram para o Sistema e que, no entanto, encontram-se afastados da atividade laboral pelo fator velhice.

O valor sistêmico da Seguridade Social e das garantias Previdenciárias sugere que todos devam ser igualmente atendidos, pois trata-se de isonomia de mínimos legais. 


\section{Exclusão e inclusão social}

A exclusão é a privação das necessidades físicas e/ou mentais do indivíduo, é 'estar fora', à margem, sem possibilidade de participação, seja na vida social como um todo, seja em algum de seus aspectos, é desfiliar-se, não pertencer, são os sobrantes, os sem direitos. A inclusão torna-se viável, quando os excluídos são capazes de recuperar sua dignidade e conseguem - além de emprego e renda - acesso à moradia decente, busca atividades culturais e serviços sociais, como educação e saúde. Esta tarefa ultrapassa o âmbito dos programas de filantropia desenvolvidos por organizações não-governamentais (ONGs) e exige o engajamento contínuo do poder público por políticas pró-ativas e preventivas.

Debruçar-se nas diferenças do Sistema Previdenciário e do Sistema Assistencial, ramos da Seguridade Social, é esboçar um conjunto de direitos de cidadania inerentes ao gozo do bem de todos conforme as normas constitucionais ditadas nos artigos $1^{\circ}$. e $3^{\circ}$.

A cidadania se reconhece pelo plexo de direitos sociais contidos no artigo 6\% CF. Considera-se exclusão social a ausência e/ou vivência parcial dos direitos do cidadão. Os excluídos socialmente representam o lado inverso das políticas sociais. São os: sem-alimentação, sem-escola, sem-educação, sem-renda, sem-trabalho, sem-transporte, sem-família, sem-previdência, sem-assistência, sem-crédito, sem-moradia, semtecnologia, sem 'direitos'. A listagem não se encolhe. Coexistem no cenário brasileiro distintas acepções do termo cidadania, como também direitos de cidadania como contradições sociais vislumbradas no acúmulo dos direitos sociais por poucos, ofuscando a ética do bem-estar e realizando o mal-estar no processo distributivo.

O primeiro critério avançado pela política de inclusão previdenciária, como nova proposta, baseia-se no conceito de segurado do subregime do Regime Geral. Trata-se do trabalhador de baixa renda e aqueles sem renda própria que se dediquem exclusivamente ao trabalho doméstico no âmbito de sua residência, desde que pertencentes a famílias de baixa renda, garantindo-lhes acesso a benefícios de valor igual a um salário mínimo" (par. 12, art. 201/CF). A legislação previdenciária do Regime Especial de Inclusão Previdenciária, ou subregime previdenciário, deverá estabelecer conceito de baixa renda como elemento delimitador do acesso a essa política social, podendo ser coincidente ou não com o conteúdo de baixa renda como critério de elegibilidade para os benefícios de salário-família e auxílio-reclusão do Regime Geral de Previdência Social (RGPS). O segundo critério delimita a relação jurídica protetiva do segurado contribuinte individual de baixa renda cuja alíquota de contribuição será de $11 \%$ sobre o valor correspondente ao limite mínimo mensal do salário de contribuição.
Esse contribuinte individual não se confunde com o contribuinte individual e facultativo taxados na Lei n. 9.876/99 cuja alíquota é de $20 \%$ sobre a renda que auferir em uma ou mais empresas e o montante declarado respectivamente. Registre-se que de acordo com a regra constitucional, os benefícios serão de um salário mínimo e as alíquotas serão inferiores às vigentes no atual Regime Geral Previdenciário. O terceiro critério consiste no caráter do segurado facultativo de baixa renda que sem renda própria se dedique exclusivamente ao trabalho doméstico de sua respectiva residência, não se confundindo, por conseguinte, com o segurado empregado doméstico do Regime Geral de Previdência Social.

A desigualdade ambienta-se global e culturalmente. Forma-se pela concentração de renda, pela feminilização da pobreza sistêmica, pela baixa ocupação feminina em postos de trabalho de maiores salários, pela flexibilização do trabalho, pelo ingresso no emprego formal e conseqüente contribuição previdenciária tardia, pela redução dos direitos sociais, pelas alterações estruturais nos sistemas previdenciários provocando mudanças que na prática reduzem benefícios, aumentam contribuições e a idade de jubilamento.

\section{Trabalho, velhice e previdência social}

Reconhecem-se as dificuldades de se definir o que vem a ser população idosa. A idade na velhice foi estabelecida pelos anos vividos, os 70 (setenta) de enfado e cansaço bíblicos.

Trata-se da população que vive a última fase da vida, contudo não há idéia clara do que marca a transição entre o fim da idade adulta e o começo da última etapa. Não há dúvida de que muitos processos caracterizam essa etapa, mas o seu início é afetado pelas condições sociais, econômicas, regionais, culturais e de gênero, entre outros. No entanto, para finalidades jurídicas, define-se como população idosa a de 60 anos e mais, tal como estabelecido no Estatuto do Idoso e na Política Nacional do Idoso.

O Estatuto do Idoso, Lei n. 10.741/03, reconhece um direito iniciado com a proteção social bismarkiana (1883), do seguro velhice. Descrevendo os direitos dos idosos mencionados em diversos artigos na Constituição Federal, intenta articular um conceito de bem-estar na velhice em torno de um certo 'espírito da seguridade' com a defesa do conjunto dos aspectos da vida que incidem no processo biológico-fisiológico do envelhecimento. Repensar o estado de providência estampado na Constituição Federal de 1988. Vários aspectos podem ser articulados em conjunto ou unitariamente no Estatuto do Idoso, sem isolá-lo dos debates contemporâneos. É no cenário nacional e global 
que podemos reunir elementos suficientes para compreender o fenômeno do processo de envelhecimento em sociedades que estão atingindo níveis suficientes de qualidade de vida.

O essencial a ser compreendido pelo intérprete de direitos sociais consiste na distinção doutrinária entre os ramos contributivo, seguro social, e não contributivo, assistencial, tendo as políticas públicas para a inclusão social critérios de elegibilidade específicos tais como família protegida, conceito exclusivo de dependentes do segurado, composição da renda familiar, critério legal de baixa renda, e a eleição da população-alvo, quer dizer, aqueles que serão 'incluídos', assistidos. Para as políticas sociais resta o desafio de eliminar o caráter discriminatório da pobreza, sem reforçar os laços do indivíduo com a condição social de desassistido social, econômica e cultural.

\section{Conceito sistemático de pobreza - absoluta e relativa}

A situação de pobreza em países como o Brasil está relacionada ao nível de desigualdade e ao modelo de desenvolvimento excludente, o qual surge renovado em cada período histórico.

Segundo a abordagem tradicional, a pobreza pode ser apreendida ou medida sob duas formas: a pobreza absoluta e a pobreza relativa. Entende-se por pobreza absoluta a não satisfação de um conjunto de necessidades consideradas básicas, nutricionais e não-nutricionais. Por sua vez, abaixo da linha da pobreza relativa, estariam aqueles indivíduos que, ainda que tenham superado as necessidades básicas, vivem com um nível de renda inferior a um determinado parâmetro definido mediante a renda média de um país.

Para o Brasil, que não definiu uma linha oficial de pobreza, optou-se por mensurar o número de pobres valendo-se do critério de pobreza relativa, adaptado à realidade nacional.

Dessa forma, foram consideradas pobres todas as pessoas que vivem em famílias com renda inferior a $50 \%$ da renda média familiar per capita.

Analisando, a distribuição dos pobres nas grandes regiões brasileiras, percebe-se o peso da pobreza no Nordeste: esta região concentra $42,5 \%$ dos pobres brasileiros. No Sudeste, influenciado pelo peso demográfico de São Paulo e Minas Gerais, estão 32,4\% dos pobres. A região Sul aparece com $11,0 \%$ e a Norte com 7,4\%. O Centro-Oeste é a região que apresenta o menor número de pobres, $6,7 \%$ do total do país.

A demanda social num país de fraca distribuição de renda como o nosso, registrado e divulgado pelos estudos dos organismos oficiais como IPEA, IBGE, PNUD, PNAD tem demonstrado a urgência na con- solidação de política de inclusão previdenciária de um tipo de trabalhador, o informal urbano, aquele que se encontra fora do âmbito das regras do atual Regime Geral de Previdência Social (RGPS), portanto desprovido de proteção previdenciária e não alcançável pelas políticas assistenciais de combate à pobreza e à miséria.

\section{As desigualdades de genêro na sociedade brasileira - dados estatísticos}

A Síntese dos Indicadores Sociais de 2001 traz um perfil da mulher brasileira, com dados sobre escolaridade, média de filhos, ocupação, rendimento, posição nos diferentes tipos de família e situação na previdência social. Quando o assunto é escolaridade e rendimento do trabalho, as diferenças entre homens e mulheres são expressivas. Mesmo que ambos tenham a mesma média de anos de estudo, os homens ganham mais que as mulheres. Essa desigualdade de rendimentos se mantém em todos os estados e regiões, e em todas as classes de anos de estudo: tanto as mulheres com grau de escolarização igual ou inferior a 3 anos de estudo ganham menos (61,5\%) que os homens com o mesmo grau de escolaridade; quanto as mulheres com maior grau de escolarização (11 anos ou mais de estudo) ganham menos (57,1\% do que ganham os homens desta faixa).

Em relação às pessoas ocupadas por grupos de idade, observa-se que nas faixas de 30 a 39 anos e 40 a 49 anos, a distribuição de mulheres trabalhando é maior do que a de homens na mesma faixa etária (26,5\% e $20,8 \%$ contra $24,5 \%$ e $19,1 \%$, respectivamente).

\section{Proporção de mulheres idosas aposentadas é menor}

A proporção de mulheres aposentadas $(45,9 \%)$ é menor que a de homens $(77,7 \%)$, conseqüência do tardio ingresso delas no mercado de trabalho. As regiões com proporções maiores de aposentadas são Nordeste $(63,1 \%)$, Norte $(51,6 \%)$ e Sul $(44,8 \%)$. Há maiores proporções aposentados no Sul (80,8\%), Nordeste (79,9\%) e Sudeste $(77,9 \%)$. No Sudeste, o percentual de aposentadas $(36,5 \%)$ é bem inferior ao dos homens.

Entre as pessoas de 60 anos ou mais, o percentual de pensionistas homens $(0,8 \%)$ é bem inferior ao de mulheres $(20,7 \%)$, graças à quantidade de viúvas nessa faixa etária. Destaca-se também o percentual de mulheres que acumulam a condição de aposentadas e pensionistas $(8,8 \%)$, superior ao dos homens $(1,1 \%)$. 


\section{Mais de 1,6 milhão de mulheres acima de 60 anos de idade ainda trabalham}

A pesquisa revela também que há uma grande proporção de pessoas de 60 anos ou mais que não recebem aposentadoria e nem pensão: $20,4 \%$ homens e $24,6 \%$ mulheres. Muitos destes ainda continuam no mercado de trabalho, têm algum outro tipo de rendimento (aluguéis, por exemplo) ou são dependentes de outras pessoas. Entre as mulheres de 60 anos ou mais, 1,6 milhão $(40,9 \%)$ ainda trabalham. Entre as que possuem aposentadoria e/ou pensão, $17,3 \%$ estão ocupadas, contra $23,6 \%$ das que não possuem nenhum desses benefícios. Nos homens, os percentuais são, respectivamente, $36,3 \%$ e 77,2\%.

\section{$71,3 \%$ das mulheres que trabalham ganham até dois salários mínimos}

As informações sobre o rendimento do trabalho confirmam que as mulheres têm remuneração inferior a dos homens. A população feminina ocupada concentra-se nas classes de rendimento mais baixas: $71,3 \%$ das mulheres que trabalham recebem até 2 salários mínimos, contra $55,1 \%$ dos homens. A desigualdade salarial aumenta conforme a remuneração. A proporção de homens que ganham mais de 5 salários mínimos é de $15,5 \%$ e das mulheres, $9,2 \%$. A diferença entre homens e mulheres permanece em todas as regiões do país. No Sudeste, $61,1 \%$ das mulheres ganham até 2 salários mínimos e no Sul, essa proporção é $72,0 \%$. Entre os homens, as proporções nessas regiões são $41,8 \%$ e $49,1 \%$, respectivamente.

A proporção de mulheres dedicadas aos trabalhos domésticos (19,2\%) e que não recebem remuneração $(10,5 \%)$ é bem maior do que a dos homens ( $0,8 \%$ e $5,9 \%$, respectivamente). Há mais mulheres trabalhando como militares ou estatutárias $(9,3 \%)$ do que homens $(5,1 \%)$, o que pode ser explicado pela grande quantidade de mulheres profissionais de saúde e educação do setor público, incluídas nessa categoria. Mais de $70 \%$ da população feminina ocupada concentra-se em atividades do setor de serviços (prestação de serviços, prática do comércio, da administração pública e outros serviços). A distribuição dos homens é mais homogênea, destacando-se a atividade agrícola, que reúne quase $1 / 4$ da população masculina ocupada do país.

\section{Convenção internacional de proteção social à mulher}

Em 1919, na primeira Conferência Internacional do Trabalho, promovida pela recém-criada Organização Internacional do Trabalho (OIT), foi formulada a primeira convenção internacional que tratava de questões relacionadas à proteção à maternidade, dando início à discussão e à formulação de uma série de instrumentos internacionais, dedicados à proteção dos direitos da mulher no campo previdenciário. Desde então, a legislação de vários países vem reconhecendo, explicitamente, o direito de proteção da mulher trabalhadora, no que tange à saúde, durante e imediatamente após a gravidez, tendo em vista assegurar a sua colocação no mercado de trabalho e seus proventos. As convenções da OIT, lidando com outras contingências previdenciárias, como morte, invalidez e idade avançada, viriam a ser instituídas bem mais tarde, em 1933.

Pode-se dizer que as motivações relacionadas à discussão dos direitos da mulher no âmbito da previdência social são derivadas de dois tipos de diferenças básicas entre os sexos: as diferenças biológicas e as socioculturais. Essas diferenças podem ser entendidas, também, com base em seus efeitos, refletidos em desigualdades de acesso a benefícios previdenciários e desigualdades normativas ou de legislação previdenciária.

\section{Diferenças biológicas}

As diferenças biológicas entre os sexos, para efeitos de previdência social, ligam-se primordialmente à reprodução. Cabendo à mulher, na procriação, funções como a gestação e a amamentação dos filhos, as quais demandam tempo e cuidados médicos durante a gravidez e no período pós-natal. É, então, vista como natural a existência de benefícios diferenciados que assegurem proteção à mulher no desempenho dessas funções.

Esses mecanismos de proteção podem abranger diversas áreas, tais como estabilidade no emprego durante a gravidez e no período pós-natal; afastamento do trabalho no período pré-natal; vencimentos parciais ou integrais garantidos durante o período de afastamento; ajudas de custo para as despesas de parto; serviços de saúde antes, durante e depois do parto etc.

O princípio básico da previdência social é a manutenção de um ingresso por motivo de perda de capacidade de gerar renda, seja real (via um acidente, doença ou morte), seja presumida (pelo envelhecimento, desgaste por tempo de serviço ou desempre- 
go). Quando se observa a estrutura de mortalidade por idade é flagrante a sobremortalidade masculina, o que resulta numa esperança de sobrevida sempre maior para as mulheres. No entanto, a especificidade feminina em termos de sobrevivência não tem sido objeto de um tratamento diferenciado.

\section{Diferenças socioculturais}

O mercado de trabalho da mulher estruturouse, em suas origens, como uma extensão do trabalho doméstico. Foram então privilegiadas áreas como saúde, educação e assistência social. Essa última caracterizada por atividade filantrópica e não-remunerada durante muito tempo. Atividades urbanas consideradas extenuantes não foram abertas à mãode-obra feminina, a não ser tardiamente, e somente após avanços tecnológicos que eliminaram, pelo menos parcialmente, a necessidade de força física para a realização de certas tarefas.

O caráter temporário e/ou parcial do emprego também tem sido atributo da condição de trabalho da mulher, uma vez que o trabalho doméstico, ao absorver parte do tempo disponível pelas mulheres, exige que muitas se dediquem a outras ocupações com jornada reduzida. Essa matéria mereceu convenção da OIT (C175/1994), na qual se procura garantir para os trabalhadores em tempo parcial os mesmos benefícios previstos para aqueles de tempo integral. Nessa convenção, coloca-se que medidas devem ser tomadas a facilitar o acesso a um regime de tempo parcial para certos grupos específicos, entre eles trabalhadores com responsabilidades familiares.

Tradicionalmente, a divisão do trabalho entre homens e mulheres foi orientada para homens 'provedores' e mulheres 'com trabalho doméstico'. Apesar do massivo ingresso das mulheres no mercado de trabalho, não houve uma concomitante eliminação do papel majoritário da mulher nas lides domésticas. Alguns dos privilégios femininos no campo dos benefícios previdenciários, como idade reduzida na aposentadoria vis-à-vis a masculina, estão associados ao discurso e à prática da dupla jornada. Muitos argumentam, no entanto, que a consagração de benefícios privilegiados para as mulheres, associados ao fato de estas terem maiores encargos familiares, pode inviabilizar a própria emancipação da mulher nessas tarefas.

O Fórum Nacional da Previdência Social no ano de 2007, alcançou consensos sobre dois temas: o primeiro, relacionado à questão de gênero e ou outro referente à coordenação entre benefícios assistenciais e previdenciários. As tendências serão a manutenção da regra de aposentadoria feminina 5 (cinco) anos menos que a masculina, uma vez que as desigualdades de gênero no Brasil ainda persistem na relação renda-ocupação-posição socioeconômicas-benefícios securitários; o segundo, incluir e somar programas assistenciais à renda familiar, pela proposta do Fórum os benefícios assistenciais entrariam no cálculo da renda familiar e permaneceriam vinculados ao salário mínimo.

Registro importante das políticas sociais e os excluídos da seguridade social são os dados pela revelação da PNAD, 2006. As novidades neste século consistem no conhecimento de que as mulheres têm menos de 2 (dois) filhos em todas as classes econômicas e sociais; elas vivem mais, mas nascem mais homens no Brasil; o Sul e Sudeste mantém a qualidade e longevidade superiores perante as demais regiões brasileiras e, nos encontramos em queda substancial da natalidade e baixa mortalidade. Esses índices repercutem no pacto de gerações da Previdência e da Assistência Social culminando numa crise fiscal-demográfica que necessitará de novas políticas do Welfare.

A política do Welfare concebeu a família como núcleo da proteção social. Nos anos 1930-1970, a Europa atravessou um período denominado pela sociologia como "pai ausente", posteriormente, esse processo foi substituído pela 'morte do pai'. Essas interpretações sociológicas não explicam a desigualdade social no Brasil, mas justificam em parte, o avanço feminino nas ocupações educacionais, laborais, no acúmulo de múltiplas jornadas, na pobreza feminina, bem como no empenho e na necessidade solitária de acumulação de novos papéis como provedoras e educadoras no lar.

Esta é a sua inovação. Provocar, possibilitar políticas contínuas de atendimento relativos aos distintos processos de envelhecimento evitando a insegurança social programada.

Concluindo, é fundamental traçar políticas efetivas de inclusão social para sanar os problemas do desequilíbrio entre a população feminina e masculina, a fim de que as políticas voltadas exclusivamente para mulheres não sejam meios justificadores de uma realidade de desigualdade e pobreza.

\section{Referências}

BALERA, Wagner. O Tratado internacional e o sistema previdenciário. Revista de Previdência Social (RPS). São Pau- lo, 1995, n. 178.

. A seguridade social da Constituição de 1988. São Pau- 
lo, RT, 1989.

O valor do trabalho social. Revista Ltr, São Paulo, v. 58, n.10, outubro de 1994.

. Curso de Direito Previdenciário. 4. ed. São Paulo: Ltr,

1998.

Sistema de Seguridade Social. São Paulo: Editora Ltr, 2000

BARROS, R. P. de; MENDONÇA, R. Uma caracterização das condições de pobreza e de desigualdade no Brasil. Rio de Janeiro: IPEA, set. 1999, 11 p. (mimeo).

BELTRÃO, K.I.; CAMARANO, A. A.; KANSO, S. Dinâmica populacional brasileira na virada do século XX. Rio de Janeiro: Ipea, 2004.

BELTRÃO, K. I.; CAMARANO, A. A.; MELLO, J. L. Mudanças nas condições de vida dos idosos rurais brasileiros: resultados não-esperados dos avanços da seguridade social rural. Rio de Janeiro: Ipea, 2004.

BELTRÃO, K. I.; MEDICI, A. C.; OLIVEIRA, F. E. B. de. Mulher e previdência social. In: Seminário mulher e cidadania: rumos e descaminhos das políticas sociais. São Paulo: Abep, 1994.

BERQUÓ, Elza. Perfil demográfico das chefias femininas no Brasil. In: BRUSCHINI, Cristina; UNBEHAUM, Sandra G. (Org.). Gênero, democracia e sociedade brasileira. São Paulo: Fundação Carlos Chagas/Editora 34, p.243-265, 2002.
CAMARANO, A. A.; PASINATO, M. T. Envelhecimento, condições de vida e política previdenciária: como ficam as mulheres? Rio de Janeiro: Ipea, 2002.

CANOTILHO, José Joaquim Gomes. Direito Constitucional. Coimbra: Livraria Almedina, 1991.

COIMBRA, Feijó. Direito Previdenciário Brasileiro. Rio de Janeiro: Edições Trabalhistas, 1990.

COSTA, Eliane. Previdência complementar na seguridade social: o risco velhice e idade para a aposentadoria. São Paulo: Ed. Ltr, 2003.

Mais Previdência menos Seguridade. Site "Publicações” (NEPJUR). Disponível em: www.ucg.com.br. Acesso em: 5 abr. 2005.

LEITE, Celso Barroso. A proteção social no Brasil. São Paulo: Ed. LTr, 1986.

MARTINEZ, Wladimir Novaes. Comentários à lei básica de previdência social. São Paulo: LTr, 1995.

MEDICI, A. C. Mulher brasileira: muito prazer. In: LABRA, E. (Org.). Mulher, saúde e sociedade no Brasil. Rio de Janeiro: Vozes, 1989.

MEDICI, A. C.; AGUIAR, M. A. S. Para entender o mercado de trabalho: como se mede o emprego, o subemprego e o desemprego. Rio de Janeiro: Ibase/Santa Úrsula, 1986.

NERI, M. Políticas estruturais de combate à pobreza no Brasil. In: HENRIQUES, R. (Org.). Desigualdade e pobreza no Brasil. Rio de Janeiro: Ipea, 2000.

\section{Welfare State Protection, Class and Income in Old Age}

\section{Abstract}

The lack of income and the lack of autonomy to deal with everyday activities make senor citizens need some kind of social protection. There are, however, conceptual differences between genders, which lead them to an unfair access to welfare benefits. In this context, welfare policies acquire special relevance if one wants to change this reality of gender inequality.

Key words: social welfare; gender inequality; public policies; senior citizens; social protection.

Data de recebimento do artigo: 30-05-2008

Data de aprovação do artigo: 05-09-2008 